\title{
8
}
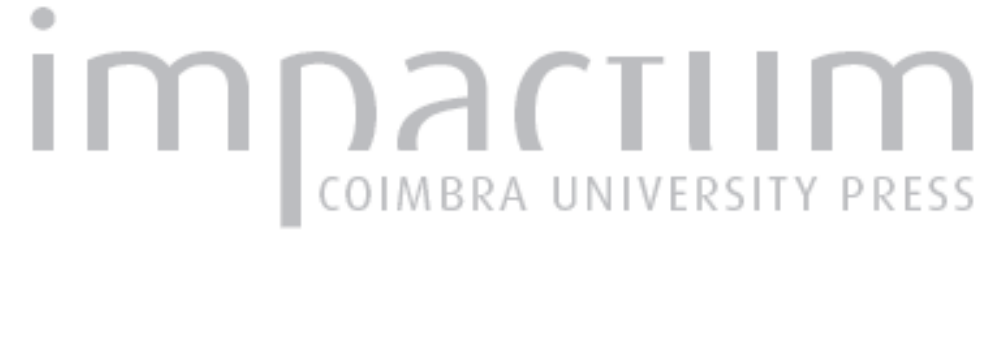

\section{Por mor de quê?: uma questão fundamental na analítica existencial de Heidegger}

\author{
Autor(es): Lima, Paulo Alexandre
}

Publicado por: Imprensa da Universidade de Coimbra

URL persistente:

URl:http://hdl.handle.net/10316.2/42851

DOI:

DOI:http://dx.doi.org/10.14195/0872-0851_50_6

Accessed : $\quad$ 26-Apr-2023 15:27:48

A navegação consulta e descarregamento dos títulos inseridos nas Bibliotecas Digitais UC Digitalis, UC Pombalina e UC Impactum, pressupõem a aceitação plena e sem reservas dos Termos e Condições de Uso destas Bibliotecas Digitais, disponíveis em https://digitalis.uc.pt/pt-pt/termos.

Conforme exposto nos referidos Termos e Condições de Uso, o descarregamento de títulos de acesso restrito requer uma licença válida de autorização devendo o utilizador aceder ao(s) documento(s) a partir de um endereço de IP da instituição detentora da supramencionada licença.

Ao utilizador é apenas permitido o descarregamento para uso pessoal, pelo que o emprego do(s) título(s) descarregado(s) para outro fim, designadamente comercial, carece de autorização do respetivo autor ou editor da obra.

Na medida em que todas as obras da UC Digitalis se encontram protegidas pelo Código do Direito de Autor e Direitos Conexos e demais legislação aplicável, toda a cópia, parcial ou total, deste documento, nos casos em que é legalmente admitida, deverá conter ou fazer-se acompanhar por este aviso.

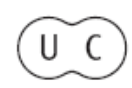




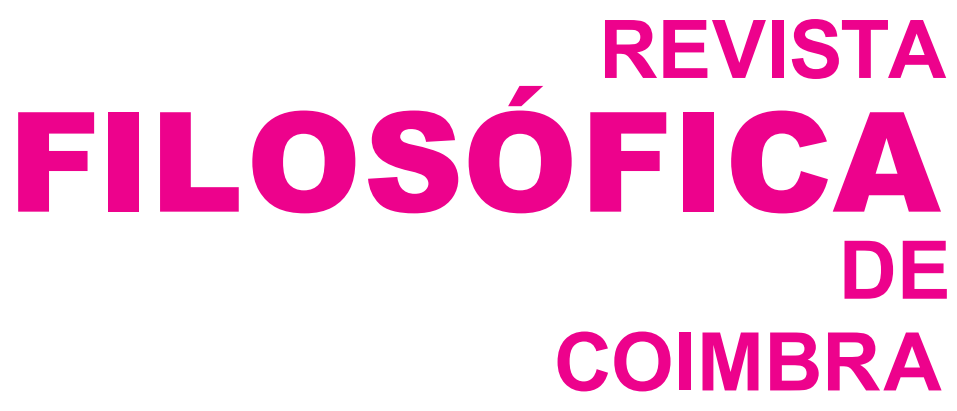

vol. 25 - número 50 - outubro 2016

vol. 25 - número 50 - outubro 2016

Fundação Eng. António de Almeida

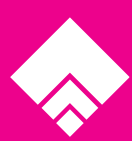




\title{
POR MOR DE QUÊ? UMA QUESTÃO FUNDAMENTAL NA ANALÍTICA EXISTENCIAL DE HEIDEGGER
}

\author{
FOR WHAT'S SAKE? \\ A FUNDAMENTAL QUESTION IN HEIDEGGER'S \\ EXISTENTIAL ANALYTIC
}

PAULO ALEXANDRE LIMA*

\begin{abstract}
Resumo: Considera-se, a partir da analítica existencial de Heidegger, o por mor de si como categoria interrogativa. Antes do mais, mostra-se que a pergunta "por mor de quê?" corresponde a uma das desformalizações possíveis da pergunta "que é a filosofia?" - enquanto esta pergunta procura alcançar uma definição da situação em que se está. Em seguida, demonstra-se como o por mor de si se acha presente nas categorias fundamentais da situação (a totalidade do si-mesmo e a totalidade dos restantes entes que aparecem ao si-mesmo) e as determina enquanto categorias interrogativas de finalidade. Por via da análise de três fenómenos (a consciência da morte, a angústia e o tédio), indicam-se algumas das formas possíveis de a situação formular explicitamente a pergunta pela sua própria finalidade - a pergunta que consiste numa das concretizações possíveis daqueloutra pergunta: "que é a filosofia?”.
\end{abstract}

Palavras-chave: Categoria interrogativa, filosofia, finalidade, Heidegger, ipseidade, por mor de si

\begin{abstract}
We will consider the category of for the sake of oneself in Heidegger's existential analytic as an interrogative category. First of all, we will show how the question "for the sake of what?" corresponds to one of the possible deformalizations of the question "what is philosophy?" - insofar as this question tries to reach a definition of the Sommaire: Dans cet article, nous
allons considérer, à partir de l'analytique
existentiale de Heidegger, la catégorie
de l'"en vue de soi-même" comme caté-
gorie interrogative. Tout d'abord, nous
chercherons de montrer que la question:
"en vue de quoi?" correspond à une des
concrétisations possibles de la question:
"qu'est-ce que la philosophie?" - en

* Instituto de Estudos Filosóficos (IEF), Universidade de Coimbra; lima.paulo alexandre@gmail.com
\end{abstract}


human situation. Next, we will point out how the category of for the sake of oneself is constitutive of the fundamental categories of the human situation (such as the totality of the self and the totality of other beings that appear to the self) and plays a major role in the determination of those categories as interrogative categories of finality. Through an analysis of three phenomena (such as the consciousness of death, anxiety and boredom) we will indicate some of the possible ways in which the human situation can explicitly ask the question of its own finality - a question that consists in one of the possible concretizations of that other question: "what is philosophy?".

Keywords: Finality, for the sake of oneself, Heidegger, interrogative category, ipseity, philosophy tant que cette question vise à parvenir à une définition de nôtre situation. Ensuite, nous essayerons de démontrer comment l'"en vue de soi-même" est présent dans les catégories fondamentales de nôtre situation (c'est-à-dire la totalité du soi-même et la totalité de tout ce qui apparaît au soi-même) et les détermine comme des catégories interrogatives de finalité. Par le moyen de l'analyse de trois phénomènes (notamment la prise de conscience de la mort, l'angoisse et l'ennui), nous allons indiquer quelques-unes des formes possibles dans lesquelles nôtre situation pose explicitement la question de leur propre finalité - en tant qu'une des réalisations possibles de cette autre question: "qu'est-ce que la philosophie?".

Mots-clés: Catégorie interrogative, en vue de soi-même, finalité, Heidegger, ipséité, philosophie

\section{Introdução}

Este estudo tem como objectivo principal uma apresentação ou exposição da categoria do por mor de si, do Umwillen seiner ${ }^{l}$.

Como podemos ver pelo título, porém, a apresentação ou exposição que procuraremos fazer não tem em vista o por mor de si, o Umwillen seiner, como um mero conceito, uma mera noção ou categoria declarativa. Em vez disso, tentaremos focar o por mor de si ou o Umwillen seiner enquanto algo que é objecto de uma pressão interrogativa quanto ao significado que tem,

1 A este respeito vejam-se $S Z$ 143, 181, 236, 327, 333, 346s., GA 24 242, 383, 418ss., 428, GA 26 237s., 240, 243ss., 249ss., 273ss., 277s., 282, GA 27 324s., 326ss., 330ss., 357, VWG 157ss., 161, 163, 165. [As abreviaturas referem-se a textos de Heidegger; são as que se utilizam em P. A. LIMA, Heidegger e a fenomenologia da solidão humana, vol. I. Lisboa: Faculdade de Ciências Sociais e Humanas da Universidade Nova de Lisboa. 2012. Tese de doutoramento, pp. 31-33. Disponível em WWW: <http://run.unl.pt/ handle/10362/8609>.] 
quanto à identidade que é a sua. Ou melhor: o por mor de si ou o Umwillen seiner vai ser objecto de consideração da nossa parte enquanto algo que envolve essencialmente (no próprio núcleo da sua constituição e identidade) uma pressão interrogativa, uma pergunta pelo sentido ou finalidade daquilo de que é uma componente fundamental.

Ora, nesta nossa tentativa de exposição da categoria do por mor de si, enquanto categoria que envolve essencialmente uma interrogação e se exprime essencialmente como interrogação, tomaremos como ponto de partida alguns dos enunciados em que se concretizou ou materializou a analítica existencial de Heidegger ${ }^{2}$.

Assim, de acordo com as indicações de Heidegger na analítica, o por mor do qual (o Worumwillen) ${ }^{3}$ corresponde a uma categoria (ou melhor: corresponde $a ̀$ categoria) fundamental do si-mesmo - ou seja, daquilo que se acha no centro, no "coração", da própria existência humana. Como é fácil de ver, porque - segundo Heidegger - o si-mesmo e aquilo que o define enquanto tal determinam fundamentalmente o sentido, a identidade, de tudo quanto aparece ao si (inclusivamente o próprio si enquanto aparece a si mesmo e constitutivamente se relaciona consigo mesmo), o por mor do qual, o Worumwillen, ao dizer respeito ao si-mesmo como sua componente essencial (isto é, como por mor de si ou Umwillen seiner), diz respeito essencialmente também a todo o aí, a todo o $\mathrm{Da}^{4}$, ou seja: determina fundamentalmente o sentido, a identidade, de todo o aí, de todo o Da, de tudo quanto aparece a um si na existência que é a sua.

Numa palavra, o por mor do qual, enquanto determina a identidade do si-mesmo, constitui também eo ipso uma determinação fundamental (ou antes: $a$ determinação fundamental) da existência no seu todo.

Ora, se assim é, isso quer dizer então que, na constituição do si-mesmo e da existência humana no seu todo, toma parte enquanto determinação fundamental algo que se caracteriza essencialmente por se exprimir como pergunta, como interrogação.

Mas, além disso, se a pergunta, a interrogação, inerente ao por mor do qual também é inerente ao si-mesmo e à existência no seu todo (como a analítica de Heidegger nos diz que é), então aquilo que verdadeiramente está em questão, aquilo que verdadeiramente é objecto de pergunta, interrogação, na

2 Sobre o conjunto de textos que a analítica existencial compreende e o período de tempo durante o qual foi desenvolvida, veja-se LIMA, Heidegger, vol. I, 56-58.

3 Vejam-se GA 20 360, 379, 382, SZ 86s., 123, 143, 145ss., 191, 193s., 228, 297s., $334,336,359,414$.

4 A propósito desta noção vejam-se GA 64 34, GA 20 150ss., 205ss., GA 21 26, 222, SZ 132, 133, 135, GA 24 20, 23s., 32, 36s., 108ss., 118ss., 140, 142ss., 152s., 156ss., 168s., 349-350, 354, 432, GA 26 123, 192s., GA 29/30 95ss., 477ss., 519, KPM 216s., 220, 222. 
categoria constitutivamente interrogativa do por mor do qual, do por mor de si, é o próprio si, a própria existência como um todo.

Em suma, a categoria do por mor do qual, do por mor de si, pode também ser expressa (e, vendo bem, fica mais adequadamente expressa) na pergunta "por mor de quê??". Este "quê" exprime o carácter enigmático do próprio si, da própria existência, por mor de que fundamentalmente se é.

No quadro da analítica existencial, a questão a que estamos a procurar introduzir não é uma questão qualquer; nem é apenas uma das muitas questões relevantes da analítica. Ela representa, antes, a sua questão central, a questão que a desencadeia, que faz dela uma analítica existencial: um empreendimento que procura definir a estrutura fundamental da existência humana. Por isso, ao examinarmos esta questão (ao considerarmos 1. até que ponto ela se acha sempre já em funcionamento na existência humana, 2. como pode ser expressamente suscitada, 3. que efeitos pode ter sobre o si-mesmo e todo o aí com que o si-mesmo permanentemente está confrontado, etc.), estaremos ao mesmo tempo a examinar quer a analítica existencial enquanto empreendimento filosófico quer a própria existência de que a analítica existencial nasce 5 .

\section{A pergunta "que é a filosofia?"}

Para compreendermos a plena expressão do por mor de si, temo-lo considerado como categoria interrogativa, isto é, como categoria que envolve uma interrogação, ou melhor, que se exprime enquanto pergunta e enquanto formula a pergunta "por mor de quê?".

Mantenhamo-nos no terreno das perguntas, das interrogações.

De facto, se considerarmos com um mínimo de atenção todo o complexo de enunciados que perfaz a analítica existencial de Heidegger, verificamos que há uma pergunta fundamental que a move e que a atravessa do princípio ao fim (umas vezes expressamente, outras vezes inexpressamente). Mas, ao contrário do que dissemos atrás (o que, como veremos já de seguida, de modo algum torna falsas as nossas declarações anteriores), o mais das vezes essa pergunta fundamental não aparece - quando aparece - como a pergunta "por mor de quê?", mas antes como a pergunta "que é a filosofia?"

5 Cf. GA 608 .

${ }^{6}$ Quanto a esta pergunta vejam-se GA 56/57 12, 15ss., GA 58 1s., 27, 210, 239, 254, GA 59 29, 32, 39s., 149, 171, 175, 183s., GA 60 7s., 10, 34, GA 61 12, 21, 57, 67, 113s., 169, 197, GA 62 323, PIA 237, GA 63 18, 110, GA 19 245ss., 252ss., 257, 531s., 610, GA 20 10, 110, 186, GA 23 16, 34, 207, 211, GA 24 5, GA 25 6, GA 26 9, 274, GA 27 3, 15, 380, 401, GA 28 214s., WM 122, GA 29/30 6, 231s., 415s., UV 7, KPM 37, GA 31 19, BKL 28. 
por mais estranho que isso possa parecer (por mais distante que pareça a relação entre a pergunta "por mor de quê?" e a pergunta "que é a filosofia?"), é esta última interrogação que se acha na base da primeira e constitui o princípio, a condição de possibilidade, da formulação dela. Segundo Heidegger, com efeito, a pergunta "por mor de quê?" constitui-se ou formula-se como contracção da pergunta, de âmbito mais universal e formal, "que é a filosofia?". Isto significa que a pergunta "que é a filosofia?" se constitui ou formula a partir de um âmbito de possibilidade tão puramente tal (a partir de um âmbito de formalidade tão puramente formal ${ }^{7}$ ) que a pergunta "por mor de quê?" consiste, segundo Heidegger, em apenas um dos seus desenvolvimentos ou uma das suas concretizações possíveis. Noutros termos - e como procuraremos ver melhor mais adiante -, a pergunta "por mor de quê?" corresponde a uma das formas possíveis de apercepção, de auto-reconhecimento ou auto-identificação, da pergunta "que é a filosofia?": da pergunta pela situação em que se está. ${ }^{8}$

Dito isto, temos de ver então que é que está em causa na pergunta "que é a filosofia?", na pergunta pela situação em que se está - para assim podermos compreender melhor a pergunta "por mor de quê?" e também em que termos pode ser considerada uma contracção ou uma desformalização possível da pergunta "que é a filosofia?" (sc. do âmbito de pura possibilidade ou de pura formalidade por relação com o qual tal pergunta é suscitada).

Comecemos, então, por determinar que é que, na pergunta "que é a filosofia?" (na pergunta pela situação em que se está), consiste no elemento propriamente interrogativo.

Assim, uma das componentes essenciais dos fenómenos interrogativos (dos fenómenos de pergunta) é a componente da indefinição ou indeterminação que se experimenta em relação àquilo que é objecto de interrogação, de pergunta. Por outras palavras, se X ou Y é objecto de pergunta, de interrogação, isso quer dizer que algo nele (até mesmo ele próprio na identidade fundamental que tem) não se acha pelo menos plenamente definido, antes se acha indeterminado: a exigir esclarecimento, justificação. ${ }^{9}$

7 Sobre a formale Anzeige vejam-se GA 56/57 12ss., GA 58 248, 262s., GA 59 62, 74, 80, 85, 172, GA 60 55, 57, 59s., 62ss., 91s., 147, AKJ 10, GA 61 19s., 32ss., 59ss., 141s., 171s., 174, GA 62 17, 49, GA 63 80, GA 17 250, SZ 116, 231, 313, GA 29/30 425, 429ss., $B K L$ 37. O carácter central da formale Anzeige na formação do pensamento de Heidegger é defendido insistentemente por T. KISIEL, The Genesis of Heidegger's Being and Time. 2nd ed. Berkeley/ Los Angeles/ London: University of California Press, 1995, 19s., 49, 52, 151s., 164s., 172s., 233, 250, 313s., 447, 455, 497, 505, 529 et passim.

8 A respeito da noção de Situation veja-se GA 29/30 207, 215, 224.

9 Quanto à concepção heideggeriana do fenómeno interrogativo vejam-se $S Z$ §2 e GA $17 \S 10$ a). 
Ora, quando Heidegger fala da pergunta "que é a filosofia?" - e a põe como ponto de partida de toda a analítica existencial (de todos os seus desenvolvimentos e articulações) ${ }^{10}$-, não está a falar de algo diferente desta experiência de indefinição ou indeterminação, de falta de esclarecimento ou justificação. Mas, vendo bem, aquilo que na pergunta "que é a filosofia?" é objecto de interrogação (e, nesse sentido, se manifesta como algo indeterminado, a precisar de esclarecimento e justificação) não é irrelevante neste contexto, antes consiste justamente no que é decisivo. Pois, neste caso, a peculiaridade do objecto da pergunta muda radicalmente a determinação do fenómeno interrogativo em causa.

Para compreendermos de que peculiaridade se trata e que mudança radical com isso se produz, consideremos aquilo que está implicado na pergunta pela situação em que se está, pois essa pergunta corresponde a uma das formulações possíveis da pergunta pela filosofia tal como se acha concebida no empreendimento da analítica existencial.

Quando Heidegger considera a pergunta pela situação em que se está, enquanto forma de expressão da pergunta pela filosofia, a indefinição ou a indeterminação (a ausência e a precisão de esclarecimento ou de justificação) que se experimentam no momento em que se fica tomado pela pergunta em causa dizem respeito à "posição" ou "localização" de si mesmo no "meio" de algo mais, de algo mais vasto.

Há, portanto, desde logo duas determinações que são absolutamente decisivas para se poder perceber que é que se acha em causa no acontecimento da pergunta pela situação em que se está:

- Em primeiro lugar, o acontecimento ou a experiência desta pergunta vive-se como acontecimento ou experiência do estar posicionado, localizado, situado em relação a algo mais, a uma totalidade mais vasta.

- E, em segundo lugar, no acontecimento ou na experiência da pergunta pela situação em que se está acha-se fundamentalmente em causa um acontecimento ou uma experiência do si-mesmo enquanto tal, quer dizer, do ser afectado por si, no núcleo de si (enquanto se é precisamente um acontecimento ou uma experiência $d a$ situação em que se está, $d o$ encontrar-se situado em relação a uma totalidade).

Mas, porque se trata de uma pergunta pela situação em que se está, não se pode perder de vista o facto de esse acontecimento ou essa experiência da situação e do si-mesmo da situação ser um acontecimento ou uma experiência em que a situação e o si-mesmo que intrinsecamente a constitui e intrinsecamente está constituído por ela aparecem como algo indeterminado,

10 A este propósito veja-se LIMA, Heidegger, vol. I, 63-411. 
como algo que exige determinação. Todavia, mais do que a situação e o si-mesmo da situação (ou porque a situação e o si-mesmo da situação estão intrinsecamente constituídos por relação com a totalidade no "meio" da qual se encontram), é a própria totalidade em questão que na pergunta pela situação surge como algo enigmático, como algo de que falta esclarecimento. E é, segundo Heidegger, a indeterminação ou a indefinição da totalidade da situação (o seu carácter enigmático) que arrasta consigo em problematicidade a própria situação e o próprio si da situação que por ela se definem.

O que propriamente está em questão na pergunta pela situação, quando se experimenta a situação em que se está como questão que nos afecta enquanto cada um de nós é um si-mesmo, é a pergunta pela definição e pelo sentido 1) da situação, 2) do si-mesmo da situação e 3) da totalidade da situação. Mas, como podemos ver, "que é a situação?", "que é o si-mesmo da situação?", "que é a totalidade da situação?" são perguntas cujo objecto ainda não se acha definido - de sorte que não se percebe bem sobre que é que incidem as perguntas em causa (as perguntas em que se desdobra a pergunta fundamental pela situação, pela filosofia). Isso deve-se, vendo bem, ao facto de só a resposta às perguntas agora formuladas poder esclarecer aquilo sobre o qual elas próprias incidem, aquilo que elas próprias têm como objecto. $\mathrm{Ou}$ melhor: a indefinição que caracteriza a pergunta pela situação é de tal ordem que é a própria pergunta pela situação que na sua tensão constitutiva para esclarecer a situação se vai esclarecendo a si (se vai de certo modo "inventando" ou "criando" a si) - e, nessa mesma tensão, também o seu objecto na complexidade que ele parece encerrar. Segundo Heidegger, portanto, é $a$ partir da pergunta pela situação, pela filosofia - é a partir da formalidade, da indefinição que caracteriza a pergunta em causa - que a situação, o si-mesmo da situação e a totalidade da situação se podem progressivamente ir definindo. $\mathrm{E}$, nesse sentido, é também a partir desse movimento de auto-esclarecimento, que é inerente à pergunta pela situação (pela filosofia), que a pergunta pela situação (pela filosofia) se pode ir apercebendo de si mesma como pergunta pelo por mor de si.

Para se entender como é que isso se processa, importa considerar

1) a noção de "si-mesmo" e

2) o modo como tal noção implica uma outra: a de "por mor de si".

\section{Ipseidade, fim e sentido}

\subsection{Si-mesmo}

Comecemos, então, por ver quais são os aspectos fundamentais do si-mesmo que Heidegger põe em evidência como determinações que vão ga- 
nhando forma a partir do movimento de auto-esclarecimento do próprio si que se experimenta enquanto si formal.

O primeiro aspecto que, segundo Heidegger, importa destacar no que diz respeito ao si-mesmo é que constitui essencialmente o si a circunstância de se executar ou expressar de cada vez como relação de si a si. Isto é, a primeira característica fundamental do si-mesmo, de acordo com a analítica existencial, consiste no facto de haver uma afecção de si por si mesmo que se manifesta ou exprime sob a forma de um "eu”, que torna possível que cada um de nós diga "eu". 11

Ora, para Heidegger, esta relação de si a si que constitui essencialmente o si-mesmo não corresponde a uma relação teórica, especular, de pura assistência do si a si mesmo. É, com efeito, uma das peculiaridades da analítica existencial de Heidegger (um dos aspectos em que a analítica mais consegue afirmar a sua originalidade na história da filosofia ${ }^{12}$ ) a concepção segundo a qual a relação constitutiva do si consigo mesmo se institui primariamente por via da execução ou da vivência concreta dessa relação. Noutros termos, a relação constitutiva do si-mesmo, a relação de si a si que o constitui, em vez de assumir a forma da pura espectação de si por si mesmo, caracteriza-se por ter no seu centro ou no seu núcleo um interesse do si por si, pelo que é de si. Isto significa que, no quadro da analítica existencial, o si-mesmo se define primária e fundamentalmente pelo facto de a cada instante estar a tratar de si, pela circunstância de em cada acção que realiza estar em causa para $\mathrm{si}^{13}$.

Mas isto ainda não é tudo. Pois, vendo bem, poderia acontecer, como vimos, que o si-mesmo se caracterizasse por uma relação de si a si e que essa relação de si a si estivesse marcada de cada vez pela execução concreta de um interesse fundamental de si por si - e, no entanto, tudo isso resultar ou ter resultado de uma escolha (de uma escolha consciente) do si-mesmo. Ora, segundo Heidegger, não é de todo em todo isso que sucede. Na verdade, não se trata de uma escolha do si-mesmo, mas de algo (de uma circunstância, de uma condição de si) com que o si-mesmo se depara e com que o si-mesmo inevitavelmente tem de lidar. Esta inevitabilidade relativa à circunstância de o si-mesmo dar consigo sempre já a ser e a ser sob a forma do interesse por

11 A respeito da Jemeinigkeit vejam-se BZ 6, 8, GA 21 229, SZ 42s., 53, GA 24 184, 243, GA 26 242, GA 31 130. A propósito da sua precedente Jeweiligkeit vejam-se GA 63 23, 48, 87, GA 64 47s., BZ 5, 6, 8, 11, 13-14, 16, GA 18 32, 180, 186, 195, 246, 350, GA 20 205s., 325.

12 Quanto à originalidade filosófica da analítica existencial veja-se LIMA, Heidegger, vol. I, 63-411.

13 Cf. $S Z 12,42$. 
$s i$ é aquilo a que Heidegger chama a facticidade (Faktizität ${ }^{14}$ do si. Segundo Heidegger, a facticidade que é inerente ao si-mesmo caracteriza-se não só pela circunstância de o si dar sempre já consigo a ser o que é (estar sempre já adiantado a si no que diz respeito ao reconhecimento do seu facto de ser e do seu modo de ser), mas também e fundamentalmente pela circunstância de não poder não ser e não poder ser senão no modo como é.

Dito isto, há ainda um outro aspecto essencial a destacar. A saber, o de que o si-mesmo - o si-mesmo que a cada instante é na forma do tratar de si, na forma da execução concreta do interesse por si que intrinsecamente o caracteriza - não se esgota de cada vez no presente de si, na tarefa particular que se acha num dado momento a realizar. Sucede, antes, que o si-mesmo, no próprio momento em que se encontra a realizar uma determinada tarefa, está de cada vez sempre já projectado para lá de si, para o futuro de si, para o si que pode ser. Para Heidegger, com efeito, o si-mesmo deixa-se caracterizar fundamentalmente como ser-possível (Möglichsein), pela possibilidade (Möglichkeit) que é..$^{15}$ Isto quer dizer que o si-mesmo está de cada vez sempre já em trânsito para lá da situação em que se acha em cada tempo presente, para lá da tarefa que em cada tempo presente se encontra a realizar.

Mas isto ainda não é tudo no que diz respeito à caracterização do si-mesmo como possibilidade ou ser-possível. Pois, vendo bem, nas caracte-

14 A propósito da Faktizität vejam-se GA 58 162, 171, 173, 256s., GA 59 19, 37, 83ss., 85, 87, 173s., 184, GA 60 9, 93s., 116s., 118s., 121s., 138s., 145s., 192, 196, 201, 213, 215s., 217, 220, 228, 230s., 241ss., 249, 252ss., 259, 263, 265s., 280, 283, 293s., 298s., 303, AKJ 22, 29ss., 32, GA 61 2, 70, 76s., 87s., 90, 93ss., 97, 99ss., 114ss., 117s., 123s., 128, 131ss., 137ss., 140, 142, 148, 150, 152, 159ss., 168, 170, 176s., 180, 183ss., 187, 195, GA 62 27, 50, 68, 74, 113, 150, 176, 180s., 181, 211s., 226s., 275s., 277s., 289s., PIA 346, 351, 356s., GA 63 3, 7, 9, 14ss., 20s., 26, 29, 35s., 65, 105, 109, 111, GA 64 43, 51s., 61s., 73, 80s., 86, GA 17 35, 106, 288s., GA 19 352, 532, GA 20 208, 304, 402s., 408, GA 21 213, 233, 409, 414, SZ 56, 134s., 145, 179, 180s., 190ss., 221s., 229, 252, 276, 284s., 328, 348, 350, 404, GA 24 217s., 395, 399, 419s., GA 26 142, 198, 217, 268, 270, GA 27 146, 279, 312, 316, 325s., 331, 338ss., GA 28 145s., 246, 259, VWG 139, UV 9, 12, GA 31 273, 283, 285, 291s., BKL 28ss., 36ss., HJB 26s. Sobre a génese e a importância da noção de Faktizität em Heidegger vejam-se H. TIETJEN, "Philosophie und Faktizität. Zur Vorbildung des existenzial-ontologischen Ansatzes in einer frühen Freiburger Vorlesung Martin Heideggers", Heidegger Studies. 2 (1986), 11-40, C. JAMME, "Heideggers frühe Begründung der Hermeneutik", Dilthey-Jahrbuch. 4 (1986-1987), 72-90, T. KISIEL, "Das Entstehen des Begriffsfeldes «Faktizität» im Frühwerk Heideggers", Dilthey-Jahrbuch. 4 (1986-1987), 91-119, KISIEL, The Genesis, 19s., 23, 26ss., 30s., 34s., 116, 136s., 496s., M.J. CARVALHO, "Fichte, Heidegger and the Concept of Facticity", in D. BREAZEALE, ROCKMORE, T. and WAIBEL, V. (eds.), Fichte and the Phenomenological Tradition. Berlin/ New York: Walter de Gruyter, 2010, 223-260.

15 Heidegger diz também que o si-mesmo se caracteriza pelo $Z u$-sein - vejam-se GA 20 205s., 208s., 220s., 286, 325, 340, SZ 42, GA 29/30 215, 246, 407, GA 31254. 
rísticas da possibilidade e do ser-possível, enquanto características essenciais do si-mesmo, o que está implicado é sobretudo que aquilo que o si-mesmo pode ser (a possibilidade que o si-mesmo pode realizar como possibilidade de si e para a qual o si-mesmo se acha na tensão que intrinsecamente o constitui) corresponde, segundo a analítica de Heidegger, ao que o si-mesmo mais propriamente é, ao "lugar" que o si-mesmo espontaneamente reconhece como a "sede" da sua identidade própria e por relação com o qual se define ou determina de cada vez na execução de cada tarefa do interesse por si.

Há, portanto, uma distância entre aquilo a que podemos chamar o si-mesmo fáctico (o si-mesmo de cada tempo presente, considerado naquilo que de cada vez já é) e o si-mesmo-a-haver (o si-mesmo para que o si-mesmo fáctico sempre já tende, mas que ainda não é plenamente).

Ora, quando Heidegger fala da possibilidade e do ser-possivel como características essenciais do si-mesmo, está no fundamental a falar desta condição elástica, extática, do si que vive o seu "já" numa tensão constitutiva para o a-haver onde "jaz" a sua identidade, a "morada" do seu ser pleno.

Mas, se ficarmos por aqui, parece que, quando falamos do a-haver onde "jaz" a identidade própria do si-mesmo, estamos a falar do a-haver imediato de cada tarefa que o si executa em cada momento presente. Não é, todavia, disso que estamos a falar. Este a-haver de que falamos, quando falamos do a-haver para que o si-mesmo tende como para o "lugar" do seu ser pleno, não é um a-haver parcial ou regional, mas antes um a-haver total - $o$ a-haver total, o a-haver da totalidade do horizonte da possibilidade ou do ser-possivel do si-mesmo.

Define esta totalidade do a-haver-de-si o facto de ela ser formal, isto é, o facto de pelo menos à partida não estar plenamente determinado qual é o seu termo, para que é que encaminha, em que é que efectivamente depõe. Há, porém, algumas determinações que, por via do movimento de auto-esclarecimento a que inicialmente nos referimos, reduzem o grau de formalidade desta totalidade do a-haver-de-si e, com isso, a indefinição ou o enigma que oportunamente vimos que se experimenta na pergunta pela situação em que se está. Ora, essas determinações - que (embora mantenham um elevado grau de formalidade) de algum modo o permitem reduzir, uma vez que definem um pouco mais precisamente a totalidade enigmática que se dá a experimentar na pergunta pela situação - são a maximização e a superlativação do si. Tais determinações permitem-nos perceber melhor que é que está em causa na relação do si-mesmo com a totalidade enquanto totalidade-do-si-a-haver. Pois, vendo bem, a totalidade da possibilidade ou do ser-possível, com que o si-mesmo constitutivamente se relaciona como quem se relaciona com o mais próprio de si, consiste na totalidade das etapas-a-haver da maximização ou da superlativação do si possivel. Isto significa, dito de outro modo, que o si-mesmo possível para que o si-mesmo 
fáctico constitutivamente tende, o si-mesmo possível que o si-mesmo fáctico de cada vez projecta como o si que tem de ser e lhe pertence ser, é nada menos do que o si maximizado, superlativado: é nada menos do que o si qualitativamente maximizado, qualitativamente superlativado.

Por aqui já conseguimos ver porque é que se disse que as determinações da maximização e da superlativação do si-mesmo reduzem de certo modo a formalidade e a indefinição que se experimentam na pergunta pela situação. É que a maximização e a superlativação, sendo ainda assim formais e tendo ainda assim um elevado grau de indefinição, correspondem de algum modo a formas de atribuição de um rosto ao que de anónimo há na totalidade enigmática que se revela na pergunta pela situação. Mais exactamente, as duas determinações em questão constituem modos de definição de um rumo, de caracterização mais precisa do teor do termo da totalidade para que o si-mesmo essencialmente se encaminha.

Ora, as duas determinações em causa definem a tal ponto o rumo do si, a direcção em que o si caminha, que, mais do que orientarem o si positivamente para aquilo que está em jogo obter (para tudo quanto o pode maximizar, superlativar, majorar), elas permitem ao si identificar também aquilo que se trata de evitar - quer dizer: elas conferem também uma espécie de orientação negativa à execução concreta do si.

Percebe-se, assim, um pouco mais claramente de que totalidade se trata quando se fala da totalidade da possibilidade ou do ser-possível do si-mesmo, da totalidade-do-a-haver-de-si. Ela é, designadamente, a totalidade no termo da qual o si fáctico de cada vez projecta o si maximizado ou superlativado para que se encaminha, que tem de ser, que lhe pertence ou lhe é devido ser.

Mas, como temos dito, as determinações da maximização e da superlativação do si-mesmo mantêm um elevado grau de formalidade - e um elevado grau de formalidade que se manifesta no facto de, apesar de se falar de maximização e de superlativação, não se conseguir perceber bem a que é que isso em verdade corresponde, que é que efectivamente é capaz de realizar esse "ideal" do máximo e do superlativo na existência concreta de cada si-mesmo.

Ora, o movimento de auto-esclarecimento da situação em que se está - o movimento em que a analítica existencial de Heidegger consiste - tem uma base fenomenal concreta para identificar a maximização e a superlativação do si, a formalidade essencial que as caracteriza. Pois o modo como o si-mesmo de cada vez executa as suas tarefas e se relaciona com os restantes entes no curso da execução dessas tarefas é tal que dá sinais de uma relação constitutiva do si-mesmo com o superlativo ou com o máximo de si - ou pelo menos com algo que é susceptível de ser interpretado dessa forma.

Com efeito, se considerarmos com um mínimo de atenção o que sucede na execução das tarefas do si-mesmo, na lida do si-mesmo com as situa- 
ções por que vai passando, podemos verificar que cada tarefa particular em execução, cada situação por que o si-mesmo passa, tende para lá de si, está numa relação fundamental com as tarefas que se acham para lá de si, com as tarefas que num determinado sentido a complementam ou completam.

Há, portanto, uma relação do si-mesmo com a tarefa que de cada vez está a executar - mas há, também, de cada vez uma relação com o para-lá dessa tarefa: na forma de uma relação com outras tarefas complementares ou com outras tarefas que simplesmente são diferentes dessa e não fazem parte daquilo a que Heidegger chama um mesmo trajecto do cuidado (Besorgensweg) ${ }^{16}$. Mas, neste contexto, sucede também o seguinte: não só a totalidade de um mesmo trajecto do cuidado, mas também as diferentes totalidades dos diferentes trajectos do cuidado estão fundamentalmente marcadas por um para-lá delas - um para-lá delas que tem justamente o seu terminus ad quem último ou final na totalidade do a-haver-de-si formal da maximização e da superlativação. Sucede, todavia, ainda o seguinte - e este é um aspecto decisivo: a totalidade de um mesmo trajecto do cuidado e as diferentes totalidades dos diferentes trajectos do cuidado não só remetem de cada vez e sempre para um para-lá delas, mas também se revelam a si mesmas de cada vez como insuficientes para o efectivo cumprimento da petição ou do quesito de maximização ou de superlativação que essencialmente caracteriza aquilo a que chamámos o si-mesmo fáctico.

Esta parece ser, pelo menos em parte, a base fenomenal a partir da qual se pode identificar algo assim como uma tensão constitutiva do si-mesmo fáctico para a sua maximização, para a sua majoração ou para a sua superlativação. A insuficiência da realização de uma determinada tarefa ou de um determinado em-causa do si-mesmo (a insatisfação que cada tarefa particular ou cada em-causa particular deixa no si-mesmo) é, portanto, interpretada como forma de manifestação do máximo ou do superlativo, da relação constitutiva e tensiva do si com a sua maximização ou com a sua superlativação.

Efectuado este breve percurso, as determinações da situação, do si-mesmo da situação e da totalidade da situação - as quais estavam por determinar quando caracterizámos a pergunta pela situação na sua plena formalidade - ganharam agora contornos um pouco mais definidos. Trata-se de contornos que, a despeito da sua profunda formalidade (a despeito de deixarem ainda muito em aberto todo um percurso possível de instâncias de determinação adicionais), permitem formular mais claramente que é que está em causa na pergunta pela situação e que é que constitui os seus diversos elementos.

O si-mesmo já não se percebe apenas como a entidade que se experimenta como auto-afecção confusa e formalíssima, mas sim como um si-mesmo

16 Sobre esta noção vejam-se GA 63 94, GA 6421. 
fáctico que se caracteriza pela sua relação constitutiva e tensiva com a totalidade da maximização ou da superlativação do si-mesmo-a-haver. A totalidade da situação, por seu turno, já não corresponde simplesmente àquilo no "meio" do qual a situação e o si-mesmo da situação se acham, antes corresponde justamente à totalidade da maximização ou da superlativação do si-mesmo-a-haver por que o si-mesmo fáctico e a situação fáctica do si-mesmo se definem no seu ser próprio. Enfim, a situação também já não é a mera "posição" ou a mera "localização" de um si-mesmo no "meio" de uma totalidade de identidade e de sentido indefinidos, mas antes a "posição" ou a "localização" intermédia ("a meio caminho") de um si-mesmo que constitutivamente tende para a totalidade da maximização ou da superlativação de si.

Mas, com isto, não é só a situação (nem são só os seus elementos constitutivos) que ganha mais nítidos contornos: é também a determinação do por mor de si, a determinação do Umwillen seiner. Pois, como parece resultar claro, o por mor do qual, o Worumwillen (e tanto quer dizer: aquilo por causa do qual, aquilo para o qual ou em vista do qual), não é senão o si-mesmo para si mesmo. Ou seja, numa palavra: o por mor do qual, o Worumwillen, é um por mor de si mesmo, um Umwillen seiner selbst. Trata-se, porém, de um por mor de si mesmo, de um Umwillen seiner selbst, com um grau de determinação mais preciso: trata-se, designadamente, de um por mor de si mesmo, de um Umwillen seiner selbst, que diz respeito a um si-mesmo que se define fundamentalmente como totalidade-de-si-mesmo-a-haver. Assim, o que está em causa para o si-mesmo - aquilo em vista do qual o si-mesmo sempre já age, aquilo por causa do qual o si-mesmo é o que é, aquilo para o qual o si-mesmo tende como para o mais próprio de si - é justamente a totalidade-de-si-mesmo-a-haver enquanto totalidade de um si maximizado ou superlativado. Ora, este por mor de si, este Umwillen seiner, não é uma característica que o si-mesmo passa a possuir independentemente do modo de ser que antes disso de todo o modo já possui. Sucede, antes, que o si-mesmo é o que é justamente enquanto por mor de si, enquanto Umwillen seiner: é o por mor de si, o Umwillen seiner, que inaugura ou instaura o modo de ser próprio do si-mesmo - o que quer dizer também: é como por mor de si, como Umwillen seiner, que o si-mesmo de cada vez sempre já se executa ou exprime.

As breves incursões que temos feito na caracterização do si-mesmo não são, todavia, suficientes para pôr na pista do pleno significado do por mor de si. Pois, vendo bem, as considerações que até aqui fizemos restringiram-se de certo modo à esfera do si-mesmo em sentido estrito - e, nesse sentido, deixaram ainda de fora um âmbito bastante decisivo no que diz respeito à determinação do por mor de si, a saber: o âmbito dos entes com que o si-mesmo de cada vez sempre já constitutivamente se relaciona. Na verdade, só depois de considerarmos também esse âmbito de realidade (numa consideração que, 
naturalmente, não poderá tocar senão alguns dos aspectos fundamentais do âmbito de realidade em questão) ficaremos então em condições de perceber minimamente a efectiva dimensão do por mor de si e até que ponto, segundo Heidegger, o por mor de si determina o sentido do si-mesmo, bem como o de todo o horizonte de manifestação a que o si-mesmo sempre já está intrinsecamente ligado.

\subsection{Por mor de si}

Vejamos, então, que é que está em causa quando se fala aqui de um âmbito de realidade que não é o do si-mesmo, mas o de algo com que o si-mesmo intrinsecamente se relaciona.

Ora, segundo Heidegger, o si-mesmo, que estivemos a caracterizar em alguns dos seus traços essenciais, não é um ente que se acha fechado em si, na sua própria esfera, de tal modo que só tem acesso ao que é de si, em sentido estrito, e a nada mais do que isso. Não. Pelo contrário, Heidegger sustenta que o si-mesmo se caracteriza - e se caracteriza fundamentalmente - por estar numa constitutiva relação com algo mais para além da esfera estrita de si. Isso quer dizer, noutros termos, que o si-mesmo não é um ente extático apenas no sentido em que a sua relação consigo envolve um "saimento" para fora de si enquanto si fáctico em direcção à totalidade-de-si-a-haver, mas também no sentido em que se caracteriza fundamentalmente por estar "saído" para fora de si em direcção àquilo que, em sentido estrito, não é si mesmo, ou seja: por estar "saído" de si em direcção aos restantes entes.

É neste sentido que se pode falar do si-mesmo como algo que se caracteriza por ser o centro ou o "coração" do aparecer. O si-mesmo é, para Heidegger, o "portador" de um aparecer ou de um aparecimento, de uma manifestação de uma multiplicidade que não se restringe à multiplicidade das aparições de si a si. A multiplicidade daquilo com que o si-mesmo está constitutivamente em contacto inclui a multiplicidade das aparições do si a si mesmo, mas também - e de uma forma tão essencial para o si-mesmo quanto as aparições de si a si - a multiplicidade das aparições dos outros e das coisas na diversidade dos seus géneros.

O si-mesmo é, se assim se pode dizer, feito de aparecer - e totalmente feito de aparecer. Isso significa, mais precisamente, que 1) a relação do si a si mesmo é feita de aparecer (ou seja: a sua relação consigo consiste no aparecer do si fáctico enquanto tal ou tal a caminho da totalidade-de-si-mesmo-superlativado-a-haver) e 2) a relação do si com os demais entes é feita de aparecer (quer dizer: corresponde a uma relação tal que o aparecer desses entes, o aspecto ou a identidade fundamental que os caracteriza no aparecer em causa, é o aspecto ou a identidade de algo que é meio num trânsito para a totalidade-de-si-mesmo-superlativado-a-haver). 
Assim, o si-mesmo é totalmente feito de aparecer - e o aparecer de que o si-mesmo é totalmente feito é o aparecer de uma totalidade: a totalidade-de-si-mesmo-superlativado-a-haver. $\mathrm{O}$ si-mesmo caracteriza-se, portanto, por estar numa relação constitutiva com uma totalidade de aparecer e, nesse sentido, caracteriza-se também por ser (enquanto si fáctico) apenas um momento dessa totalidade de aparecer. Deste modo, o si-mesmo fáctico é o centro ou o "coração" do aparecer (da totalidade do aparecer fundada na totalidade-de-si-mesmo-superlativado-a-haver que de certa forma sempre já aparece), sim - mas é, ainda assim, um momento dessa totalidade-de-si-mesmo-superlativado-a-haver que funda todo o aparecer, depende dessa totalidade, está essencialmente determinado por ela. E é assim de tal forma que todas as características do si-mesmo que anteriormente considerámos se exprimem ou manifestam de cada vez sempre já no aparecer de que o si é o centro essencialmente determinado por esse aparecer.

Com efeito, o si-mesmo relaciona-se consigo como algo que aparece a si por intermédio de uma relação prévia com o aparecer da totalidade-de-si-mesmo-superlativado-a-haver. É essa relação prévia (primária, original ou originária) com o aparecer da totalidade-de-si-mesmo-superlativado-a-haver que funda (inaugura, instaura ou institui) a relação de "interesse" do si consigo. Mais: é justamente nessa relação originária com o aparecer da totalidade-de-si-mesmo-superlativado-a-haver que o si-mesmo sempre já dá consigo a ser e é nessa relação que o si tem de ser o que é e pode ser o que de antemão já é sem ainda o ser plenamente. O si-mesmo, enquanto centro ou "coração" do aparecer da totalidade-de-si-mesmo-a-haver, está de cada vez sempre já ultrapassado pelo aparecer dessa totalidade, está de cada vez sempre já a ter de carregá-lo como seu fardo ${ }^{17}$ e como seu destino.

Mas, como dissemos, o por mor de si, o Umwillen seiner, não diz respeito apenas à relação do si-mesmo consigo, à esfera do si-mesmo em sentido estrito: o por mor de si, o Umwillen seiner, diz respeito também ao âmbito de realidade com que o si-mesmo intrinsecamente se relaciona, ao âmbito de realidade dos demais entes.

Ora, o que acabámos de ver permite-nos perceber mais claramente como assim é. Pois, na verdade, é a partir da própria projecção da totalidade de si (da totalidade que, como considerámos, é a de um si-mesmo-superlativado-a-haver) que o si-mesmo vê ser aberto para si o acesso aos restantes entes. De facto, constitui um elemento fundamental da projecção da totalidade-de-si-mesmo-superlativado-a-haver (quer dizer: constitui um elemento fundamental da relação do si consigo em toda a sua amplitude) a circunstância de a tensão inerente a essa projecção para a totalidade projectada consistir numa tensão ou num encaminhamento que tem lugar - como Heidegger refere - no

17 A este respeito veja-se $S Z$ 134s., 284, 345, 371. 
"meio" do ente (inmitten des Seienden) ${ }^{18}$. Ou seja: não acontece simplesmente que, por um lado, o si-mesmo tenha uma relação consigo - uma relação pela qual o si-mesmo constitutivamente se acha em tensão para a totalidade da superlativação de si - e, por outro lado, tenha uma relação com o que não é si mesmo, com os restantes entes (como se se tratasse de duas notas meramente complementares ou adicionais). Sucede, antes, que é $n a$ própria projecção da totalidade da superlativação de si (quer dizer: $n a$ própria relação do si consigo) que se inaugura o acesso do si-mesmo ao demais - a esse demais que assim se caracteriza justamente como o "com-o-qual" ou como o "no-meio-do-qual" da tensão da totalidade projectada da superlativação de si. Por outras palavras, a totalidade da multiplicidade dos restantes entes que aparecem ao si-mesmo e com que o si-mesmo essencialmente se relaciona corresponde à totalidade da multiplicidade de algo que cumpre as funções de "terreno" ou de "meio" da tensão de superlativação que é inerente ao si e, desse modo, corresponde à totalidade da multiplicidade de algo que está sempre já a ser ultrapassado (sob a forma de um Überstieg ${ }^{19}$ ) pela projecção da superlativação-de-si-a-haver e a ser compreendido no seu sentido à luz de tal projecção.

Ora, se assim é, isso significa que a determinação fundamental dos entes com que o si-mesmo se relaciona (a determinação de identidade ou de sentido de tais entes) tem como condição de possibilidade da sua manifestação a projecção da superlativação-de-si-a-haver. Isto é, a totalidade desses entes (na multiplicidade de géneros que compreende: quer se trate de outros, quer se trate de coisas) equivale a uma totalidade de funções da tensão de superlativação inerente ao si-mesmo - ou, se se preferir: equivale à totalidade de algo que (de diversos modos) está ao "serviço" de tal tensão, se compreende à luz dela, desempenha um qualquer papel na sua execução (ora como algo que é benéfico e que há que procurar, ora como algo que é prejudicial e que há que evitar, ora como algo que é muito indiferente, pouco indiferente, etc.). Podemos assim dizer que, em certo sentido, a totalidade da multiplicidade dos entes que não são o si-mesmo é compreendida pelo si-mesmo sempre já como totalidade de uma multiplicidade de funções possiveis na tensão global de superlativação de si, no empreendimento de si.

18 Cf. $W M$ 110, 112, GA 29/30 208, 224.

19 Cf. $V W G$ 138, 139, 157. Sobre noções afins como Transzendenz e ursprüngliche Transzendenz vejam-se GA 24 23, 85ss., 230, 248s., 311, 316, 379, 413, 418, 424ss., 428s., 436, 443s., 447, 452, 459s., GA 25 23, 93, 219, 315s., 318, 334, 371s., 381, 409, GA 26 20, 24s., 70, 109ss., 169s., 194, 203ss., 209-215, 232ss., 240-247, 251, 269s., 272, 274-281, GA 27 206-213, 217s., 222s., 239, 305ss., 312, 315ss., 322s., 325s., 328-331, 337s., 341s., 352-355, GA 29/30 446s., KPM 40, 67s., 73s., 82s., 85, 87, 97, 101, 104, 110, 112ss., 115, 118s., 122, 128s., 135, 154s., 158s., 182, 184, 190ss., 199, 228ss., 235s., 254s., $V W G 126,134,137$ s., 141, 156, 158s., 161s., 163-170, 172, 174. 
Isto significa, dito de outro modo, que a totalidade dos entes que não são o si-mesmo está sempre já compreendida pelo si-mesmo a partir de categorias de finalidade (a partir das categorias do Wozu e do Um-zü20). Quer dizer, o que cada um dos entes que não são o si-mesmo é corresponde a algo cuja determinação fundamental de identidade e de sentido consiste no papel que aquilo para que serve (o seu para-o-qual) desempenha - e pode, como referimos, desempenhá-lo de diferentes modos - na tensão do si-mesmo para a realização ou para o cumprimento da finalidade mais final que é a superlativação de si. Neste sentido, o Wozu e o Um-zu (as determinações que caracterizam o aspecto fundamental dos entes que não são o si-mesmo) equivalem a determinações sempre já compreendidas à luz de e em retorno de um contacto ou de uma relação com a categoria transcendental fundamental do Umwillen seiner. Vendo bem, é precisamente esta categoria transcendental fundamental do Umwillen seiner que equivale à categoria de mundo $(\text { Welt })^{21}$ - tal como é precisamente a sua componente de tensão, enquanto projecta a totalidade-de-si-mesmo-superlativado-a-haver ou o mundo, que equivale à categoria do ser-no-mundo (In-der-Welt-sein $)^{22}$.

Dito isto, resulta mais ou menos claro que a estrutura da finalidade atravessa e constitui todas as componentes essenciais da totalidade do aparecer enquanto este diz respeito a uma situação. De acordo com o que vimos, o si-mesmo mostra-se desde logo como um ente que de raiz se acha marcado pela determinação da finalidade ou do fim, uma vez que aquilo que o faz

20 A este propósito vejam-se GA 20 231, 259, 359, GA 21 18, 219s., GA 24 415s., 418, GA 29/30 331s.

21 Esta categoria desdobra-se em três: a) Selbstwelt, b) Umwelt e c) Mitwelt. Sobre a Selbstwelt vejam-se GA 58 31, 33, 39, 45s., 56ss., 60ss., 68s., 76s., 84s., 86s., 89ss., 95s., 98s., 101, 139, 147, 170ss., 175s., 178, 180, 197, 206s., 211, 221, 223, 227, AKJ 30, 34, GA 61 94, 105, PIA 240, GA 63 102s., GA 64 25, 31, GA 20 333, GA 24225. A respeito da Umwelt vejam-se GA 56/57 72s., 85ss., 98, 208, GA 58 3, 14, 33, 39, 46, 51ss., 58, 60, 62, 96, 135, 170, 197ss., 206, 227, AKJ 30s., 34, GA 61 94, 96, 98, 129s., PIA 240, 268, GA 63 86, GA 64 19s., 25, 31, GA 20 229s., 247s., 250, 252s., 256s., 258, 260s., 269, 307, GA 21 104, 147, 214s., 217, 337, 364, 412, GA 24 233, 439. Quanto à Mitwelt vejam-se GA 58 33, 39, 56, 60, 62, 86, 97, 170, 197ss., 221, 227, GA 60 11, 13, 87s., 101, 115, 117-119, 138, 140, 227, 229-237, 242, 245, 249, AKJ 30, 34, GA 61 94, GA 63 93ss., 98, 102, GA 64 24s., 31, GA 19 386, GA 20 333, GA 21 222, GA 25315.

22 Sobre o In-der-Welt-sein vejam-se GA 61 85ss., 97, GA 63 80, 85, 102, GA 64 19, 23, 25, 48, 100, 112, GA 17 30, 34, 50s., 54, 66, 99, 100, 139, 197, 200, 207, 236s., 241, 244, 246, 248, 250, 262, 265s., 269, 271, 273s., 283, 325, 354, 362, 378, 390s., GA $18139,246,248,269,271,355,357 \mathrm{~s} ., 359,361,365,381,388,395$, GA 20 210s., 267, 278, 286, 288s., 292, 394s., 296, 298, 306, 314s., 325s., 332, 402, 421, GA 21 212s., 225, 228s., 291, 401, 406, SZ 53, 63ss., GA 24 234, 236, 239ss., 248s., 308, 383, 391, 393, 408s., 413s., 414, 417, 420-426, 428, 444, GA 26 170, 212s., 216s., GA 27 240, 305ss., 315s., 322s., 327s., 337, 342, 344ss., $V W G$ 140-142, 166s. 
(aquilo que está no centro da sua identidade) é a tensão para a totalidade de si que ele próprio projecta - e, nesse sentido, o si-mesmo define-se como cumprimento de um fim que representa o sentido último do seu ser-o-que-é. Mas, como acabámos de ver há pouco, é também o âmbito de realidades não correspondentes ao si-mesmo que se encontra de raiz marcado pela categoria da finalidade ou do fim, na medida em que toma o seu sentido fundamental da função que desempenha na tensão constitutiva do si.

Chegados a este ponto, podemos compreender já alguns aspectos do movimento de auto-esclarecimento da situação em que se está, posto em marcha pela analítica existencial. De acordo com esse movimento de mais precisa apercepção da situação em que se está, a situação em questão percebe-se como algo que tem no seu centro a categoria fundamental do por mor de si, ao ponto de a categoria fundamental do por mor de si determinar de raiz o sentido de todos os elementos que a partir da caracterização da pergunta formal pela situação vimos que constituem a situação.

Mas, se estamos lembrados, a nossa proposta é a de uma exposição ou apresentação da categoria do por mor de si como categoria interrogativa - e não, se assim se pode dizer, como categoria declarativa. Ora, apesar de todos os passos que já demos, a categoria do por mor de si ainda não apareceu como expressão de uma pergunta ou interrogação, de sorte que é isso mesmo que se trata de averiguar no que se segue. Pois, vendo bem, a categoria interrogativa do por mor de si - ou a pergunta "por mor de quê?" - é uma categoria decisiva e sem a identificação da qual (quer dizer: sem a identificação disso mesmo por mor do qual se é) quer a situação quer todos os elementos que a formam ficam ainda e sempre inteiramente por esclarecer.

\section{Por mor de quê?}

Nesta tematização da categoria do por mor de si enquanto categoria interrogativa, importa começar por averiguar como é que a pergunta ou a interrogação "por mor de quê?" se acha em funcionamento habitualmente. Pois, se atentarmos na questão, tudo parece indicar que o por mor de si como categoria interrogativa está, o mais das vezes, ausente da nossa existência.

O que parece acontecer a este respeito, no entanto, é que a aparente ausência da pergunta "por mor de quê?" no curso da nossa existência habitual não significa uma ausência real dessa pergunta. É um facto que, habitualmente, a pergunta "por mor de quê?" se encontra "calada" ou "silenciada", não se expressa ou não se manifesta com nitidez. Mas isso significa precisamente que a sua vigência é uma vigência "silenciosa" - de um "silêncio", porém, que nem por isso enfraquece a efectividade da vigência daquela pergunta, antes a fortalece justamente porque faz que a atenção não se dirija para ela. 
Assim, está implicado na analítica existencial de Heidegger que a pergunta "por mor de quê?" se encontra presente em todos os momentos da existência - e encontra-se presente em todos os momentos da existência justamente enquanto pergunta.

Isso resulta claro se se considerar, por exemplo, o facto de habitualmente (e apesar de toda a inatenção em relação à questão da existência e da sua estrutura fundamental, que habitualmente perdura) o modo como nos relacionamos connosco e com o demais implicar em si - expressa ou inexpressamente - uma pretensão de sentido, isto é: uma pretensão de se saber que é que se acha em causa na existência, porque é que ou para que é que se existe.

Isso é bastante manifesto no próprio modo como habitualmente nos achamos mergulhados nas nossas tarefas e nas nossas actividades. Ainda que à primeira vista possa parecer que se trata de uma imersão completa em tais tarefas ou actividades (como a de escrever uma conferência, uma tese académica, o projecto de ser professor ou investigador, etc., etc.), a execução dessas tarefas ou actividades implica - expressa ou inexpressamente - uma hipótese, um pressuposto ou uma evidência de que elas são a condição (ou, pelo menos, uma parte indispensável) do cumprimento da tensão de superlativação do si-mesmo que cada um de nós é.

Há - é o que isto significa - um quesito de sentido (uma pergunta pelo para-o-qual-último da existência) e, ao mesmo tempo (ou, se assim se pode dizer: imediatamente, automaticamente), uma resposta a esse quesito, a essa petição de sentido. Trata-se de uma resposta que a existência dá espontaneamente a si mesma e que implica que o modo como ela sempre já se acha a ser (aquilo que nela nos achamos sempre já a fazer) é o modo de se realizar plenamente. A existência é um "negócio que cobre os seus custos"23. A existência, tal como se executa habitualmente, parece ser de facto um "negócio sustentável" e "condenado ao sucesso".

Ora, se isto representa, por uma parte, um grau significativo de absorção (de Aufgehen, como Heidegger lhe chama) ${ }^{24}$, na medida em que há uma

23 O texto que se acha entre aspas é uma alteração da nossa parte de um excerto de Schopenhauer segundo o qual "a vida é um negócio que não cobre os seus custos". Heidegger refere-se a esse excerto de Die Welt als Wille und Vorstellung II em GA 5830.

24 Vejam-se GA 58 16, 33, 49, 108s., 112s., 115, 117s., 124s., 162, 180, 217, 255, GA 60 200, 227s., 239s., GA 61 90, 94, 103, 123, 132, 142, 194, GA 62 17, PIA 355ss., 359ss., 362, 366, GA 63 103, 112, GA 64 23, 28s., 41ss., 51, 59, 68s., 71, 73s., 76, 87, 89ss., 100, GA 17 84, GA 18 108, GA 20 137, 250, 260, 267s., 286, 289, 329, 336, 339, 350s., 352s., 407, 420, GA 21 156s., 230s., GA 22 8, SZ 51, 54, 71s., 75s., 111, 113, 125, 129s., 167, 172, 175s., 184, 189, 192, 203, 222, 224s., 252, 270, 315, 322, 354s., 369, 389, GA 24 250, 463, GA 26 174, GA 27 135, 148, 333, 357, 359, GA 29/30 153, 513, Zoll 205s., 256. 
aceitação da tese espontânea ou automática da existência e está o mais das vezes ausente um questionamento dessa tese - por outra parte, há uma espécie de dinâmica entre o quesito ou a petição de sentido para a existência e a imediata ou automática resposta que a existência dá a si mesma a respeito desse quesito ou dessa petição. Ora, é justamente em tal dinâmica que se pode identificar uma não completa absorção do si-mesmo da existência naquilo que faz, no modo como concretamente se executa. E, nesse sentido, é também em tal dinâmica que se podem abrir "janelas de oportunidade" para um questionamento do modo espontâneo de se existir, para uma relação crítica ou questionante com o para-o-qual-último da existência. Isto não quer dizer, como já pode resultar claro, que a categoria do por mor de si é originalmente uma categoria declarativa e que só depois de se desenvolver uma relação crítica ou questionante com ela é que se torna numa categoria interrogativa. Não. A categoria do por mor de si é uma categoria originalmente interrogativa - o que acontece na relação crítica com ela é que se passa a manifestar plenamente como a categoria interrogativa (como a pergunta) que sempre já é: e isso precisamente porque se revela como pergunta não respondida, como pergunta suspensa da sua resposta (se se quiser: como intenção interrogativa esvaziada do seu preenchimento).

O por mor de si corresponde, portanto, a uma categoria essencialmente interrogativa - à categoria que, na sua qualidade de interrogativa, está no centro da existência e mobiliza a existência para a satisfação do quesito ou da petição em que consiste. Ora, se isto sucede sempre já no curso da existência, continua a suceder na modalidade da existência que Heidegger concebe como a filosofia. Para Heidegger, com efeito, a filosofia é justamente pelo menos um dos modos em que se desencadeia uma relação expressa e crítica com a pergunta "por mor de quê?" enquanto tal. Noutros termos, a tendência de esclarecimento (a Erhellungstendenz) ${ }^{25}$ que sempre já vigora na existência - e que, como dissemos, a existência espontânea ou automaticamente satisfaz de um determinado modo - surge na sua máxima expressão, levada às suas últimas consequências e na sua máxima radicalidade, na filosofia. A filosofia, segundo Heidegger, caracteriza-se justamente como um contra-movimento (Gegenbewegung ${ }^{26}$ que faz oposição a uma tendência espontânea da existência para se dar a si mesma respostas que não "passaram pelo crivo" de um questionamento radical do seu sentido e da sua eficácia. É, com efeito, a atitude de questionamento (de Fraglichmachen, como Heidegger diz) ${ }^{27}$ em relação ao para-o-qual-último da existência (mais exactamente, em relação às respostas espontâneas ou automáticas da existên-
25 Cf. GA 61152.
26 Cf. PIA 245.
27 Cf. PIA 245. 
cia à pergunta que sempre já faz pelo para-o-qual-último de si mesma) que equivale à filosofia. E, se a filosofia põe em questão o para-o-qual-último da existência - se a filosofia faz expressamente a pergunta "por mor de quê?" sem a aceitação automática de respostas insuficientes ou insatisfatórias -, então isso significa que a filosofia questiona ou torna problemática a estrutura fundamental de sentido de todo o aparecer sem qualquer excepção. Por isso mesmo, Heidegger define a filosofia como a suscitação de uma problematicidade absoluta (de uma absolute Fragwürdigkeit) ${ }^{28}$.

De entre as formas possíveis de ruptura ou quebra da evidência de sentido espontânea da existência, Heidegger dá destaque pelo menos a três: são elas a consciência da morte $(T o d)^{29}$, a angústia $(\text { Angst })^{30}$ e o tédio (Langeweile) ${ }^{31}$. Nota bene: esses três modos de ruptura ou quebra da evidência em questão não são os únicos, nem parece haver condições para sustentar que são os mais adequados para pôr na pista do que constitui uma autêntica (mesmo que apenas momentânea) relação interrogativa com o por mor de si na forma da pergunta "por mor de quê?". Constituem, todavia, modos privilegiados do desencadeamento dessa relação interrogativa, momentos de oportunidade (Augenblicke, no sentido heideggeriano do termo) ${ }^{32}$ para perguntar: "por mor de quê?'"

Como é natural, não podemos analisar aqui desenvolvidamente cada um dos três fenómenos em causa (consciência da morte, angústia e tédio). Restringir-nos-emos à evidenciação de como cada um desses fenómenos se assim se pode dizer, no momento do seu "assalto" - estão em condições de afectar o si-mesmo e a categoria do por mor de si que essencialmente o constitui (e que habitualmente o constitui na forma de uma evidência inquestionada sobre a que é que isso corresponde) ao ponto de o si questionar e poder passar a questionar tal evidência, o sentido sempre já pressuposto do por mor de si mesmo. Por outras palavras, a consciência da morte, a angústia e o tédio - cada um a seu modo - são para Heidegger, neste contexto, fundamentalmente formas de crise ou de colapso do sentido habitual de se ser um si-mesmo, de se ser por mor de si mesmo. De tal sorte que não é um outro sentido do si ou um outro sentido do por mor de si que vem substituir o sentido habitual. Enquanto crises ou colapsos da forma de sentido natural ou habitual, a consciência da morte, a angústia e o tédio põem o si-mesmo

28 Vejam-se GA 58 36, 42, 173, GA 61 2, 34, 37, 56, 93, 150ss., 174ss., 190, 195, 197, GA 62 37, PIA 348ss., GA 63 17, BZ 17, 28, GA 17 76s., GA 21 23s., GA 25 2, GA 26 14, GA 27 200, GA 29/30 28ss., 31ss., 34, 84, 244ss., 255, GA 31 116, 130, 143, HBB 7.

29 Cf. e.g. GA $20 \S \S 33-34, S Z \S 47, \S \S 49-53$.

30 Cf. e.g. $G A 20 \S 30, S Z \S 40$.

31 Cf. e.g. $W M 110, G A$ 29/30 120, 121, 202, 207, 222.

32 Cf. e.g. $S Z$ §65, §68a, GA 29/30 224, 229. 
que cada um de nós é perante a possibilidade do não-sentido, perante a possibilidade do absurdo. $\mathrm{O}$ que de modos diversos - mas todos eles muito agudos - se dá a ver na consciência da morte, na angústia e no tédio é o carácter enigmático, o carácter por decifrar do si-mesmo e do por mor de si que o constitui e que constitui a raiz do então aparente pseudo-sentido de todo o aparecimento em geral. O que na consciência da morte, na angústia e no tédio se pergunta ou pode passar a perguntar é, segundo Heidegger: "por mor de quê, então?", "porquê haver algo como eu, como o si-mesmo que eu sou?", "porque, afinal, tudo isto?"

De facto, a tomada de consciência de que a existência não se prolonga indefinidamente põe ou pode pôr em crise, faz ou pode fazer entrar em colapso o sentido de um projecto como o do si-mesmo, o sentido de um projecto de superlativação de si que parece contar com um indefinido prolongamento do tempo.

A angústia, por seu turno, tal como é caracterizada por Heidegger, corresponde no fundamental a uma crise ou a um colapso do sentido habitualmente constituido por via da tomada de consciência muito aguda de que as mais diversas desformalizações do empreendimento de si não satisfazem (nem parecem poder satisfazer) o quesito da superlatividade qualitativa do si-mesmo.

Mas, se na angústia continua a haver uma enorme pressão para a realização do empreendimento de si cujo sentido se acha então em suspenso, no fenómeno do tédio experimenta-se a lassidão que "abre a porta" à possibilidade da indiferença, à possibilidade de que o por-mor-do-qual já não importa - e, desse modo, o tédio parece "abrir a porta" à possibilidade da desistência, à possibilidade de se rejeitar a interpelação do por mor de si.

Como dissemos há pouco, estes três fenómenos não são apresentados por Heidegger sob a forma de únicas possibilidades de questionação autêntica e radical do sentido natural ou habitualmente constituído. São, antes, modos excepcionais, singulares, de suscitação, de incrementação e de fomentação desse questionamento. Quando Heidegger fala, designadamente, da filosofia enquanto contra-movimento ou contra-ruinância (Gegenruinanz) ${ }^{33}$, está a referir-se, a nosso ver, também à assunção consequente de momentos de oportunidade como os que acabámos de considerar. Nesse sentido, a filosofia é, para Heidegger, um ir-no-encalço de momentos de oportunidade como esses, uma insistência na experiência de questionamento em que momentos de oportunidade como esses nos depõem. Isto significa que a filosofia, assim

33 Sobre a Gegenruinanz vejam-se GA 61 152, 160, 176, 178, PIA 243, 245, GA 26 174, KPM 226-227. Quanto à Ruinanz - que se acha suposta na Gegenruinanz - vejam-se GA 58 185, GA 61 2, 18, 39, 103, 120, 121, 125, 127, 131ss., 135-140, 142, 149-153, 154, 184, 186, 195, GA 63 109, GA 21230. 
concebida, corresponde a um movimento de questionamento que se prolonga e se continua num meio profundamente marcado por um ter-sido, por um ter-acontecido. Numa palavra, tal como Heidegger a concebe, a filosofia está profundamente marcada pela sua facticidade - ela é o seu já-ter-sido, o seu já-ter-acontecido: e não parece achar-se em condições para determinar em absoluto o que necessariamente a faz, o que necessariamente a desencadeia. Quer dizer: a filosofia tem um carácter fáctico e profundamente contingente, pois sempre já aconteceu quando é "posta em marcha" e o seu ter-acontecido podia perfeitamente não se ter dado. Desta forma, a consciência da morte, a angústia, o tédio, etc., podem nunca acontecer verdadeiramente - e, mesmo que aconteçam, podem não acontecer de tal modo que motivem o questionamento que neles se experimenta.

\section{Conclusão}

Vejamos agora, à guisa de conclusão, como é que o percurso feito até aqui responde ao nosso problema inicial. Ora, de entrada, tínhamos proposto a consideração do por mor de si enquanto categoria interrogativa, o que julgamos ter mostrado já pelo menos sob a forma de um brevíssimo esboço. Mas, mais do que isso, o que "entrou em cena" ulteriormente como aquilo que importava expor ou apresentar foi a tese segundo a qual a pergunta "por mor de quê?" corresponde a uma desformalização da pergunta "que é a filosofia?" ou da pergunta pela situação em que se está. E, vendo bem, em virtude do que temos vindo a mostrar, já estamos em condições pelo menos de formular com mais clareza que tese na verdade é aquela.

Assim, de acordo com essa tese, a pergunta "por mor de quê?" não é a única possibilidade de desformalização da filosofia, mas sim apenas uma delas. Dito de outro modo, como também já referimos inicialmente, a pergunta "por mor de quê?" resulta de uma contracção numa determinada direcção da pergunta pela filosofia ou pela situação (da formalidade, da indefinição ou da indeterminação que aí se experimenta). Segundo Heidegger, nesse sentido, essa é uma das formas de a filosofia se expressar ou concretizar uma entre uma multiplicidade de outras formas, historicamente verificáveis (desformalizadas em diversos géneros de perguntas) ou ainda por vir.

Embora esta tese pareça ser demasiado abstracta, pareça carecer de uma base fenomenal sólida e de algum modo verificável, a verdade é que os três fenómenos que há pouco considerámos (a consciência da morte, a angústia e o tédio, mas possivelmente também outros fenómenos) de certo modo nos põem em contacto com a esfera de pura formalidade por contracção da qual a filosofia pode ganhar uma multiplicidade de aspectos e conformações. 
A propósito da angústia, por exemplo, Heidegger diz - em Sein und Zeit - que ela nos põe em relação com o algo mais originário (das ursprünglichste Etwas ${ }^{34}$. É verdade que Heidegger, imediatamente depois de ter produzido esta afirmação, sustenta que esse algo mais originário é o mundo enquanto tal, ou melhor, interpreta esse algo mais originário como o mundo enquanto tal. Mas isso tem que ver, em nosso entender, com a própria estratégia e com a própria economia de Sein und Zeit, pois nesse passo do $\S$ em que Heidegger analisa a angústia ${ }^{35} \mathrm{o}$ fenómeno da angústia é metodicamente utilizado para apresentar uma forma de acesso ao mundo enquanto mundo, o que significa que a categoria do mundo enquanto mundo não está a ser efectivamente questionada como aquilo que na verdade se experimenta quando se experimenta o anonimato do algo mais originário. $\mathrm{O}$ que nos parece estar em causa, no passo em questão, é que na angústia se experimenta ou se é posto perante uma esfera de formalidade cuja interpretação é susceptível de desformalizar ou contrair essa esfera numa multiplicidade de direcções: a sua interpretação como mundo enquanto tal é uma-e apenas uma-dessas desformalizações ou contracções.

O que pretendemos com isto é, como dissemos, mostrar que a tese segundo a qual a pergunta "por mor de quê?" é uma desformalização da pergunta pela filosofia (enquanto pergunta pela situação em que se está) tem ou pode ter pelo menos alguma base fenomenal. E a experiência da angústia, tal como é caracterizada por Heidegger em Sein und Zeit, parece proporcionar um contacto com a esfera de pura formalidade a que nos referimos quando falámos da indefinição ou da indeterminação que caracteriza a pergunta pela situação. Ora, a nossa tese é, mais precisamente, que - tal como em Sein und Zeit o algo mais originário que se experimenta na angústia é interpretado como mundo, em virtude da própria tese existencial de fundo da obra em questão - assim também a pergunta pela filosofia ou pela situação em que se está sofre uma contracção da formalidade que originalmente a constitui (uma contracção que vai no sentido de a interpretar como algo que corresponde à pergunta "por mor de quê??") justamente em virtude de se interpretar a situação que cai em indefinição ou em indeterminação como

34 Cf. SZ 187. A noção de ursprünglichstes Etwas, que encontramos em Sein und Zeit, imediatamente nos faz lembrar uma outra noção, muito próxima desta no seu sentido, à qual Heidegger fez referência cerca de oito anos antes, no chamado Kriegsnotsemester, a saber, a noção de "algo originário" (Ur-etwas). A noção aparece num esquema dos apontamentos de Franz-Joseph Brecht relativos ao semestre referido (cf. GA 56/57 219). Theodore Kisiel (cf. KISIEL, The Genesis, 21-22) chamou a atenção para a existência deste esquema nos apontamentos de Franz-Joseph Brecht, Gerda Walther e Oskar Becker. A Gesamtausgabe só publicou o esquema a partir da segunda edição do vol. 56/57.

35 Trata-se do $\S 40$. 
algo que se caracteriza de raiz pela categoria interrogativa do por mor de si. Numa palavra: a pergunta pela filosofia ou pela situação é desformalizável - e é desformalizada por Heidegger - na pergunta "por mor de quê?" na medida em que o próprio movimento de auto-esclarecimento da filosofia ou da situação em indefinição se caracteriza a si mesmo como algo que assenta fundamentalmente na categoria interrogativa do por mor de si, como algo que é explicável por meio dessa categoria.

Trata-se, portanto, de algo que sucede por via do próprio movimento de auto-esclarecimento da situação. É verdade que, por uma parte, há um ganho de determinação e de definição. Mas pelo menos por vezes, como parece ser o caso, um ganho de determinação ou de definição pode corresponder a uma perda de potencialidade. Um dos aspectos singulares do pensamento de Heidegger - um aspecto que transparece em pelo menos muitos momentos do seu pensamento - é um constante esforço de determinação e de definição que constantemente regressa à esfera de formalidade e de potencialidade de que nasce ou brota. O pensamento de Heidegger é, nesse sentido, um pensamento que se renova, um pensamento que permanentemente se revê. Ao não renunciar a um permanente contacto com a esfera de potencialidade $\mathrm{e}$ de formalidade em questão (com a esfera a que no vol. 56/57 se refere como a da "mais elevada potencialidade da vida"36), Heidegger não rejeita ou não desiste de um contacto incessante e renovado com aquilo que torna possível a própria historicidade do plano em que somos - e tanto quer dizer: a diversidade e a diversificação das formas como somos e das formas de apercepção do que somos. A esfera da pura formalidade ou da pura potencialidade, a que nos temos referido aqui, é assim não só o plano que torna possível as mais diversas modalidades de compreensão da filosofia, mas também aquilo por contacto com o qual pode haver igualmente outra coisa que não a filosofia.

36 Cf. GA 56/57 115: "die höchste Potentialität des Lebens". 
(Página deixada propositadamente em branco.) 